\title{
Defective Conduction of Anorectal Afferents Is a Very Prevalent Pathophysiological Factor Associated to Fecal Incontinence in Women
}

\author{
Lluís Mundet, ${ }^{1,2 *}$ Christopher Cabib, ${ }^{1}$ Omar Ortega, ${ }^{1,2}$ Laia Rofes, ${ }^{1,2}$ Noemí Tomsen, ${ }^{1}$ Sergio Marin, ${ }^{1}$ Carla Chacón, ${ }^{1}$ and \\ Pere Clavé ${ }^{1,2}$ \\ ${ }^{1}$ Unitat d'Exploracions Funcionals Digestives, Hospital de Mataró, Consorci Sanitari del Maresme, Mataró, Catalonia, Spain; and ${ }^{2}$ Centro de \\ Investigación Biomédica en Red de enfermedades hepáticas y digestivas (CIBERehd), Instituto de Salud Carlos III, Barcelona, Spain
}

\section{Background/Aims}

Fecal incontinence (FI) is a prevalent condition among women. While biomechanical motor components have been thoroughly researched, anorectal sensory aspects are less known. We studied the pathophysiology of FI in community-dwelling women, specifically, the conduction through efferent/afferent neural pathways.

\section{Methods}

A cross-sectional study was conducted on 175 women with $\mathrm{Fl}$ and 19 healthy volunteers. The functional/structural study included anorectal manometry/endoanal ultrasound. Neurophysiological studies including pudendal nerve terminal motor latency (PNTML) and sensory-evoked-potentials to anal/rectal stimulation (ASEP/RSEP) were conducted on all healthy volunteers and on 2 subgroups of 42 and 38 patients, respectively.

\section{Results}

The main conditions associated with FI were childbirth (79.00\%) and coloproctological surgery (37.10\%). Cleveland score was 11.39 \pm 4.09. Anorectal manometry showed external anal sphincter and internal anal sphincter insufficiency in $82.85 \%$ and $44.00 \%$, respectively. Sensitivity to rectal distension was impaired in $27.42 \%$. Endoanal ultrasound showed tears in external anal sphincter (60.57\%) and internal anal sphincter disruptions (34.80\%). Abnormal anorectal sensory conduction was evidenced through ASEP and RSEP in $63.16 \%$ and $50.00 \%$ of patients, respectively, alongside reduced activation of brain cortex to anorectal stimulation. In contrast, PNTML was delayed in only $33.30 \%$. Stools were loose/very loose in $56.70 \%$ of patients.

\section{Conclusions}

Pathophysiology of $\mathrm{FI}$ in women is mainly associated with mechanical sphincter dysfunctions related to either muscle damage or, to a lesser extent, impaired efferent conduction at pudendal nerves. Impaired conduction through afferent anorectal pathways is also very prevalent in women with $\mathrm{Fl}$ and may play an important role as a pathophysiological factor and as a potential therapeutic target.

(J Neurogastroenterol Motil 2019;25:423-435)

\section{Key Words}

Anorectal physiology; Evoked potentials; Fecal incontinence; Pathophysiology; Pudendal nerve terminal motor latency

Received: November 13, 2018 Revised: March 1, 2019 Accepted: March 26, 2019

(a) This is an Open Access article distributed under the terms of the Creative Commons Attribution Non-Commercial License (http://creativecommons. org/licenses/by-nc/4.0) which permits unrestricted non-commercial use, distribution, and reproduction in any medium, provided the original work is properly cited.

${ }^{*}$ Correspondence: Lluís Mundet, PhD, RN

GI Motility Laboratory, Hospital de Mataró, Carretera de Cirera, 230, Mataró 08304, Barcelona, Catalonia, Spain Tel: +34-937417700 (ext. 2748), Fax: +34-937417733, E-mail: lluismundetp@gmail.com 


\section{Introduction}

Fecal incontinence (FI) represents a major psychosocial burden for affected individuals, leading some of them to social restriction and even isolation in severe cases. ${ }^{1-4}$ Reduction in Quality of life (QoL) correlates with FI severity ${ }^{5,6}$ but may also be influenced by sex, age and presence of anxiety/depression. ${ }^{4}$

Recently reported prevalence rates in the general population estimate vary due to differences in survey methods and in definitions $^{7-9}$ and are also considered to be under-reported. ${ }^{9}$ Recently some authors have found rates from $7 \%$ to $15 \% .^{7,10,11}$ Many studies report higher prevalence in women ${ }^{12-14}$ - mainly due to childbirth ${ }^{15,16}$ —although recently, some others ${ }^{17-19}$ have reported similar rates for both genders. A prevalence of up to $24 \%$ for communitydwelling women has been reported. ${ }^{20}$

Causes of FI in adults include childbirth-related procedures for women, but also surgical coloproctological procedures carried out on fistulae, anal fissures, hemorrhoids and low anterior resection (LAR) of the rectum ${ }^{21-24}$ and, to a lesser degree, radiotherapy, diabetes, hypothyroidism, and a broad spectrum of central nervous system (CNS) disorders. ${ }^{25-27}$ Likewise, fecal consistency plays an important role in fecal continence. ${ }^{28}$

Continence mechanisms depend on various factors: the strength of several muscles and anal sealing-physical barriers, preserved anorectal sensitivity and integrity of peripheral nerves and reflexes, and sensorimotor CNS integration and sensory feedback from pelvic structures required for the triggering of continence mechanisms. Pelvic floor muscles can be accurately evaluated with anorectal manometry (ARM) and endoanal ultrasonography (EUS), while the most distal part of the peripheral motor (or efferent) neural pathway to pelvic floor muscles can be assessed using the pudendal nerve terminal motor latency (PNTML), although this technique is not accepted worldwide and under discussion. Sensitivity to rectal distention is commonly tested during ARM with a latex balloon. ${ }^{29}$ Although this technique is widely used in clinical practice, interpretation, and data acquisition depends on patients' subjective assessment. ${ }^{30}$ Rectal distention involves rectal wall mechanoreceptor activation, however it does not evaluate directly conduction through anorectal sensory afferent pathways and CNS activation. ${ }^{31}$ Objective neurophysiological techniques for assessing the integrity of afferent pathways from anorectal structures include the event-related sensory evoked potentials (SEP) to rectal and anal electrical stimulation. ${ }^{32}$ This technique has been used in healthy volunteers $(\mathrm{HV})^{32-34}$ and recent studies found objective evidence of impaired anal and rectal afferent pathways in patients with constipation $^{35}$ and with anal cancer, ${ }^{36}$ respectively. Few studies have explored SEP in FI, and even less so, the role of altered sensory pathways as a mechanism underlying FI, comparing patients with FI with $\mathrm{HV}$.

Understanding the pathophysiological mechanisms behind FI is crucial in order to select proper treatment, improve anorectal function, minimize symptoms, and eventually restore QoL. The aim of this study is to characterize the pathophysiology of FI in community-dwelling women, assessing the structure and function of anal sphincters, and conduction through afferent pathways and cortical activation in response to anorectal electrical stimulation.

\section{Materials and Methods}

\section{Study Design and Recruitment}

This cross-sectional observational study was conducted on 175 consecutive women with FI symptoms attending the motility unit of the Hospital de Mataró, Catalonia. Patients had FI symptoms between 1 and 6 months before recruitment and were excluded if they were pregnant or under 18 years of age. Additionally, $19 \mathrm{HV}$ with similar demographic characteristics to the patients but with no FI or constipation symptoms were recruited through an advertisement and studied with the aim of setting normal physiological values. All patients were studied via ARM and EUS. Two randomized subgroups of these patients were also explored by PNTML $(\mathrm{n}=42)$ and SEP ( $\mathrm{n}=38)$. HV were all studied with ARM, PNTML, and SEP. The study protocol was approved by the hospital ethics committee (code: 67/12).

\section{Etiology and Clinical Severity}

Demographic and socioeconomic data, comorbidities, and risk factors of patients and $\mathrm{HV}$ were collected as previously described. ${ }^{4}$ FI severity was assessed using the Cleveland score. ${ }^{37}$

\section{Health Status and Quality of Life Assessment}

FI-related QoL, the Spanish validated version of the Fecal Incontinence Quality of Life scale (FIQL) was used. ${ }^{38}$ This questionnaire consists of 29 items that assess 4 aspects represented by 4 different subscales: lifestyle, behavior, depression, and embarrassment. Each subscale ranges from 0 to 4 (worst QoL to non-altered QoL). ${ }^{39}$ General health-related QoL was assessed using EuroQol's EQ-5D-3L, a generic instrument that measures 5 QoL aspects: mobility, self-care, usual activities, pain/discomfort, and anxiety/ depression, and which is commonly used for a wide range of condi- 
tions, including FI. ${ }^{40-42}$ Each aspect has 3 categories: no problems, minor problems, and major problems.

\section{Pathophysiology}

\section{Pelvic floor disorders, consistency of stools, and urinary incontinence}

Baden-Walker halfway-scoring system ${ }^{43}$ was performed in order to evaluate the presence of concomitant pelvic organ prolapse. Fecal consistency was determined using the Bristol Stool Chart (1, very hard to 7 , liquid stools). ${ }^{44}$ Presence and clinical severity of urinary incontinence was assessed with the International Consultation on Incontinence Modular Questionnaire (ICIQ) score. ${ }^{45}$

\section{Anorectal manometry study}

ARM was performed using a water-perfused probe with 6 recording sites arranged circumferentially (Mui Scientific, Ontario, Canada), allowing the evaluation of functional anal canal length, maximum resting pressure (MRP), and maximum voluntary squeeze pressures (MVSP). ${ }^{29}$ The endurance of MVSP was also assessed, determining 4 types of pressure profile patterns (10 seconds duration) previously described: perfectly maintained or quite well-maintained squeeze over time (effective profiles), and 2 clearly poor sustained squeezes (ineffective profiles). ${ }^{46} \mathrm{~A}$ second catheter with a latex balloon at the top end and 4 longitudinal recording sites spiroidally distributed in 1-cm intervals (Mui Scientific) was used to measure rectal sensitivity (the balloon was inflated progressively to elicit 4 perception states: first sensation, first feeling to pass stools, constant desire to defecate, and maximum tolerable volume), rectoanal inhibitory reflex (RAIR), cough reflex, and defecatory maneuver. Normal values for MRP, MVSP, and rectal sensitivity were obtained from HV. Data was acquired using a Polygraph ID recorder and the Polygram NET software (Medtronic, Minneapolis, MN, USA). Procedures and measurements followed international standards recommended by the Spanish Motility Group (Grupo Español de Motilidad Digestiva). ${ }^{47}$

\section{Endoanal ultrasonography}

External anal sphincter (EAS), internal anal sphincter (IAS), and puborectalis structural integrity were assessed using a EUB6500-HV US ultrasound (Hitachi Medical Corporation, Tokyo, Japan). Sphincter structure was obtained in cross-sectional images at the upper, mid, and lower anal canal and findings were located in quadrants. $^{48}$

\section{Neurophysiological assessment}

Distal efferent pathway. PNTML was performed on both sides in a randomized subgroup of 42 patients and on the $19 \mathrm{HV}$ by using the St. Mark's pudendal electrode (Alpine Biomed ApS, Skovlunde, Denmark) with standard procedures. ${ }^{49,50}$ The electrode was repositioned the number of times that were necessary until assuring the largest amplitude and the shortest latency of the compound muscle action potential (CMAP) for each pudendal nerve. ${ }^{51}$ A 10-mA square-electrical pulse (duration 0.2 milliseconds [msec]) evoked well-tolerated supramaximal CMAPs in all studied participants, and so we set this stimulation intensity to ensure appropriate between-participant comparison in the data analysis.

Afferent pathway. Event-related anorectal sensory evoked potentials and sensory thresholds. In 40 patients, we examined the SEP to anal and rectal stimulation (ASEP/RSEP), and also studied in $\mathrm{HV}$ to obtain reference intervals of normality. Procedures have been previously reported. ${ }^{32,35}$ For stimulation, we used a probe provided with 2 ring electrodes $2 \mathrm{~cm}$ apart (Gaeltec Ltd, Dunvegan, Isle of Skye, Scotland) and connected to an electrical stimulator (Digitimer DS7A, Letchworth Garden City, UK). The probe was inserted into the anal canal with the more external electrode placed $1 \mathrm{~cm}$ from the anal margin for anal stimulation and $15 \mathrm{~cm}$ from the anal margin for rectal stimulation. We first calculated perception and tolerance thresholds in each person for both the anus and rectal mucosa by applying $0.2 \mathrm{msec}$ square-pulses and increasing the intensity in steps of $0.5 \mathrm{~mA}$. Perception threshold was defined as the minimum intensity perceived by the patient, while tolerance threshold as the maximum intensity tolerated. The assessment was repeated 3 times to ensure consistency. If the tolerance threshold exceeded stimulator's power (100 mA), stimulation was done at the machine's maximum intensity. To obtain SEP, intensity was set to $75 \%$ of the mean tolerance threshold and stimulation frequency to $0.2 \mathrm{~Hz}$ to avoid habituation. ${ }^{52}$ A total of 200 stimuli (separated in 4 series of 50 pulses) were applied to both the anus and the rectum. Electroencephalographic (EEG) activity was recorded using a 32-active channel cap (Electro-Cap International Inc, Eaton, OH, USA) arranged following the conventional 10-20 EEG system and referenced to the left ear lobe. The electro-oculogram was recorded with an electrode placed below the left eyelid. The EEG signal was recorded with BrainAmp (Brain Products GmbH, Munich, Germany) using a sampling rate of $500 \mathrm{~Hz}$ and a $50-\mathrm{Hz}$ notch-filter. Electrode impedance was kept below $5 \mathrm{~K} \Omega$. Patients were instructed to keep their eyes open and minimize body movements during recording. EEG signal was analyzed with BrainVision Analyzer 2.0 
(Brain Products). EEG signal (bandpass filter of 0.5-60 Hz) was segmented into $600 \mathrm{msec}$ epochs, including $100 \mathrm{msec}$ of pre-stimulus baseline. Artifacts larger than $50 \mu \mathrm{V}$ were rejected. The interval from $-100 \mathrm{msec}$ to $-20 \mathrm{msec}$ before the stimulus artifact was used for baseline correction of the post-stimulus EEG signal. Epochs were averaged to obtain the SEP, which were obtained in $\mathrm{Cz}$, the cortical site of maximum representation after anorectal stimulation. ${ }^{32,52}$ Negative and positive wave peaks related to the SEP were identified and values of peak latency and peak-to-peak amplitude were measured for all components.

\section{Statistical Methods}

Continuous variables were expressed as means (SDs), and compared with T-tests or equivalent non-parametric tests. Categorical variables were expressed as frequencies and percentages and compared with Chi-square or Fisher's exact tests. Normal range limits were calculated from data of $\mathrm{HV}$; the 5-95 percentiles were used for non-normally distributed values and the mean $\pm 2 \mathrm{SD}$ for normally distributed values. Statistical analyses were conducted using SPSS version 20.0 (IBM Corp, Armonk, NY, USA). The sLORETA software package (KEY Foundation for Brain-Mind Research, Zurich, Switzerland) was used to assess the differences in cortical localization between groups of patients and HV computed by voxel-by-voxel t-tests for independent measures. ${ }^{53}$

\section{Results}

\section{Demographics}

The mean age of our patients was $61.14 \pm 12.11$ years, the age distribution of $\mathrm{HV}$ being very similar (64.63 \pm 8.57 years) (not significant). Most common comorbidities in FI women were mood disturbances such as depression (44.57\% [78]), hypertension (35.42\% [62]), dyslipidemia (33.14\% [58]), arthrosis (25.71\% [45]), and diabetes (17.14\% [30]). There were no significant differences with $\mathrm{HV}$.

\section{Etiology and Risk Factors}

Obstetric risk factors for FI were more prevalent in our patients when compared with HV, 85.14\% (149) of patients had at least one obstetric risk factor compared with $21.05 \%$ (4) of the $\mathrm{HV}(P<$ $0.001)$. Coloproctological surgical procedures were also more prevalent in patients compared with HV. Overall, 37.14\% (65) of the FI patients suffered at least one coloproctological intervention during their lifetime; in contrast, only $10.52 \%$ (2) of the $\mathrm{HV}$ required such procedures $(P=0.021)$. Obstetric and coloproctological procedures associated with FI are shown in Table 1.

Menopause was present in $69.71 \%$ (122) of the patients with FI, 34.28\% (60) had a hysterectomy, and 5.14\% (9), cystocele surgery. In a smaller proportion of patients $(8.57 \%$ [15]) we identified neurological risk factors such as previous stroke, neurodegenerative disorders or spine surgery.

\section{Clinical Severity and Impaired Quality of Life}

Mean clinical severity measured with the Cleveland score was $11.55 \pm 3.81$. Of the patients, $6.85 \%$ (12) had mild severity, scoring $0-5 ; 31.42 \%$ (55) reported moderate FI, scoring 6-11; $47.42 \%$ (83) had severe FI, scoring 11-15 and finally, $14.28 \%$ (25) of the patients had very severe FI symptoms, scoring 16-20. According to FIQL score, incontinence reduced QoL especially in the coping and embarrassment subscales which decreased by nearly $50.00 \%$

Table 1. Etiology of Fecal Incontinence: Obstetric and Coloproctological Risk Factors

\begin{tabular}{|c|c|c|c|}
\hline Risk factors & $\begin{array}{l}\text { Patients } \\
(\mathrm{n}=175)\end{array}$ & $\begin{array}{c}\text { HV } \\
(\mathrm{n}=19)\end{array}$ & $P$-value \\
\hline \multicolumn{4}{|l|}{ Obstetric risk factors } \\
\hline Parity & $96.57 \%(169)$ & $94.73 \%(18)$ & 0.521 \\
\hline Birth weight $>4 \mathrm{~kg}$ & $21.14 \%(37)$ & $5.26 \%(1)$ & 0.130 \\
\hline Prolonged labor & $58.28 \%(102)$ & $10.53 \%(2)$ & $<0.001$ \\
\hline Large episiotomy & $60.57 \%(106)$ & $5.26 \%(1)$ & $<0.001$ \\
\hline $\begin{array}{l}\text { Delivery with } \\
\text { complications }\end{array}$ & $19.42 \%(34)$ & $21.05 \%(4)$ & 0.769 \\
\hline Forceps and/or spatula & $40.00 \%(70)$ & $15.78 \%(3)$ & 0.046 \\
\hline Cesarean section & $11.42 \%(20)$ & $5.26 \%(1)$ & 0.699 \\
\hline \multicolumn{4}{|l|}{$\begin{array}{l}\text { Coloproctological risk } \\
\text { factors }\end{array}$} \\
\hline Hemorrhoidectomy & $18.28 \%(32)$ & $0.00 \%$ & 0.047 \\
\hline Band ligation & $1.14 \%(2)$ & & \\
\hline Longo & $4.57 \%(8)$ & & \\
\hline Milligan-Morgan & $5.14 \%(9)$ & & \\
\hline Whitehead & $7.43 \%(13)$ & & \\
\hline $\begin{array}{l}\text { Has hemorrhoids } \\
\text { currently }\end{array}$ & $20.00 \%(35)$ & $0.00 \%$ & 0.027 \\
\hline Anal fissure procedures & $5.71 \%(10)$ & $5.26 \%(1)$ & $>0.999$ \\
\hline Anal dilatation & $0.57 \%(1)$ & & \\
\hline $\begin{array}{l}\text { Lateral internal } \\
\text { sphincterotomy }\end{array}$ & $5.14 \%(9)$ & & \\
\hline Anal fistula surgery & $6.28 \%(11)$ & $5.26 \%(1)$ & $>0.999$ \\
\hline Colon surgery & $9.14 \%(16)$ & $0.00 \%$ & 0.374 \\
\hline LAR & $3.42 \%(6)$ & $0.00 \%$ & $>0.999$ \\
\hline Other & $5.71 \%(10)$ & $0.00 \%$ & 0.602 \\
\hline
\end{tabular}

$\mathrm{HV}$, healthy volunteers; LAR, low anterior resection. 
(2.29 \pm 0.81 and $2.48 \pm 0.83$, respectively). Regarding health-related $\mathrm{QoL}$, our patients showed a restricted general $\mathrm{QoL}$ measured with EQ5D, especially in the pain/discomfort and anxiety/depression areas. Comparing patients' results with HV, FI patients' QoL was worse than that of $\mathrm{HV}$, the parameters of usual activities, pain/ discomfort and evolution of perceived health-state reaching statistical significance. When reducing EQ5D data to a single index (0, worst health state to 1 , best health state), patients had significantly poorer health status than $\mathrm{HV}(0.65 \pm 0.24$ vs $0.83 \pm 0.19$, respectively, $P<0.001$ ).

\section{Pathophysiology}

\section{Pelvic floor organ prolapses and urinary incontinence}

Almost half of our patients (40.25\% [64/159]) showed pelvic floor organ prolapse of some kind, cystocele and rectocele being the most prevalent (14.46\% [23/159] and 13.20\% [21/159], respectively), followed by uterine prolapse with $6.28 \%(10 / 159)$ and enterocele/vaginal vault prolapse with 5.66\% (9/159). Urethrocele was present in only 1 patient (0.62\%). In contrast, only $1 \mathrm{HV}(5.26 \%)$ was diagnosed with a cystocele, $P<0.05)$.

Regarding urinary incontinence, $48.57 \%$ of the patients with FI (85) reported symptoms compared with $21.05 \%$ (4) of the HV. Severity of urinary incontinence (ICIQ score) was $10.86 \pm 5.36$

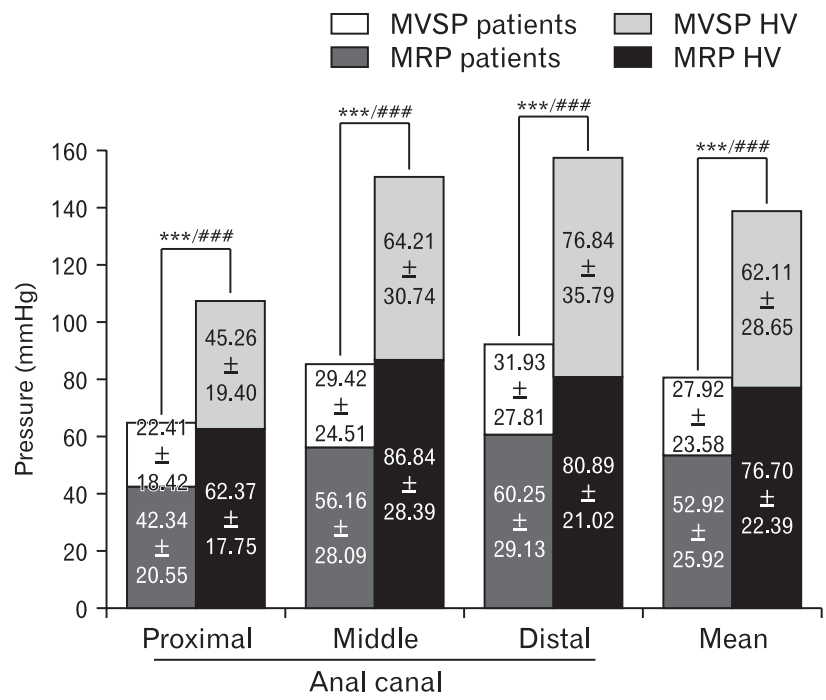

Figure 1. Data of mean resting pressure (MRP) and mean voluntary squeeze pressure (MVSP) from proximal, middle, and distal portions of the anal canal of patients and healthy volunteers (HV) studied with anorectal manometry, as well as the mean of the 3 levels. Both MRP and MVSP differences between patients and HV were statistically significant ( ${ }^{* * *} P<0.001$ for MRP, ${ }^{\# \# \#} P<0.001$ for MVSP). amongst patients, and $5.75 \pm 3.50$ in the $\mathrm{HV}$ group, $(P=0.063)$.

\section{Fecal consistency}

More than half the patients (56.00\% [98]) had loose or very loose stools (Bristol 5, 34.85\% [61]; Bristol 6, 19.42\% [34]; Bristol 7, $1.71 \%$ [3]). Of the HV, only $15.78 \%$ [3] had this kind of soft/loose stools (Bristol 5 10.52\% [2] and Bristol $65.26 \%$ [1]), differences being significant $(P<0.01)$.

\section{Anal sphincter motor function}

Resting and maximal squeeze pressures. Data acquired via ARM showed statistically significant differences in both the magnitude of MRP and MVSP when comparing patients with HV. Patients had lower resting pressure and lower maximum squeeze increments in all 3 levels of the anal canal compared with HV (Fig. 1).

Based on the reference values provided by $\mathrm{HV}$, patients' EAS and IAS function was determined. Most women patients $(82.85 \%$ [145]) showed EAS insufficiency; almost half (44.00\% [77]), IAS insufficiency, and in one third $34.28 \%$ [60]) both EAS and IAS were dysfunctional. Only 11 patients (6.28\%) with FI showed normal mechanical function of both anal sphincters (full data in Table 2).

\section{Endurance of maximum voluntary squeeze pres-} sures. To assess how MVSP was sustained over time, we used the aforementioned 4 manometric patterns when patients were asked to hold MVSP for 10 seconds. More than one third of the patients with FI (37.34\% [62/166]) showed poorly sustained MVSP (ineffective profiles). In contrast, all HV studied were able to hold proper contraction of EAS $(P<0.004)$ (Fig. 2).

In addition, half the patients with FI (49.71\% [87]) showed some kind of anorectal dyssynergia when attempting to defecate,

Table 2. Mechanical Sphincter Function Studied With Anorectal Manometry in Patients With Fecal Incontinence

\begin{tabular}{lc}
\hline \multicolumn{1}{c}{ Dysfunction } & $\mathrm{n}=175$ \\
\hline EAS insufficiency & $145(82.85 \%)$ \\
IAS insufficiency & $77(44.00 \%)$ \\
IAS and EAS insufficiency & $60(34.28 \%)$ \\
No insufficiency & $11(6.28 \%)$ \\
Anorectal dyssynergia & $87(49.71 \%)$ \\
Dyssynergia type I & $75(42.85 \%)$ \\
Dyssynergia type II & $5(2.85 \%)$ \\
Dyssynergia type III & $2(1.14 \%)$ \\
Dyssynergia type IV & $5(2.85 \%)$ \\
\hline
\end{tabular}

EAS, external anal sphincter; IAS, internal anal sphincter 


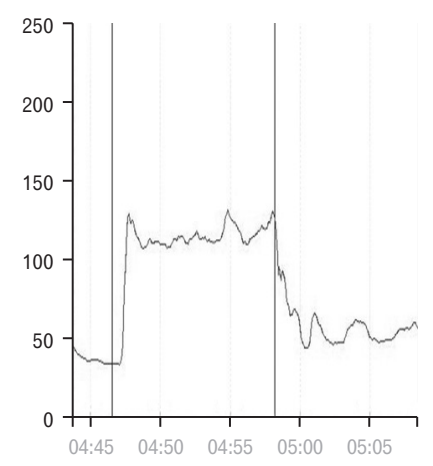

Type 1

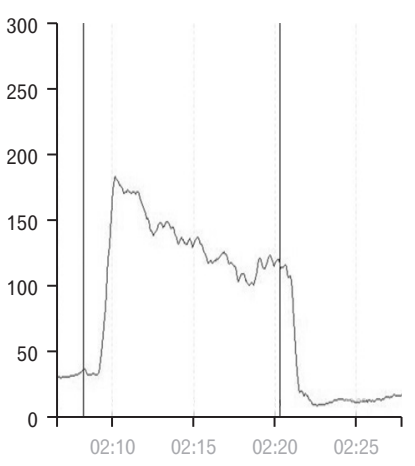

Type 2

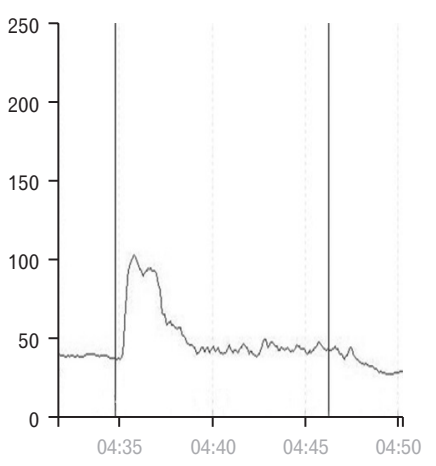

Type 3

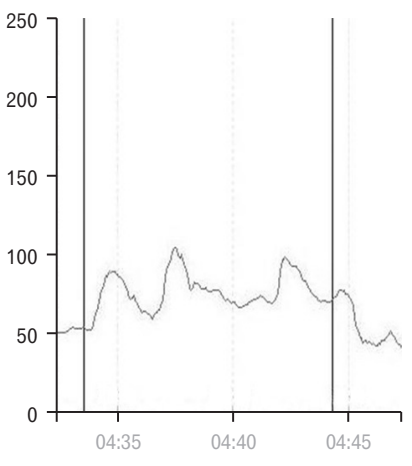

Type 4

Effective pressure profiles

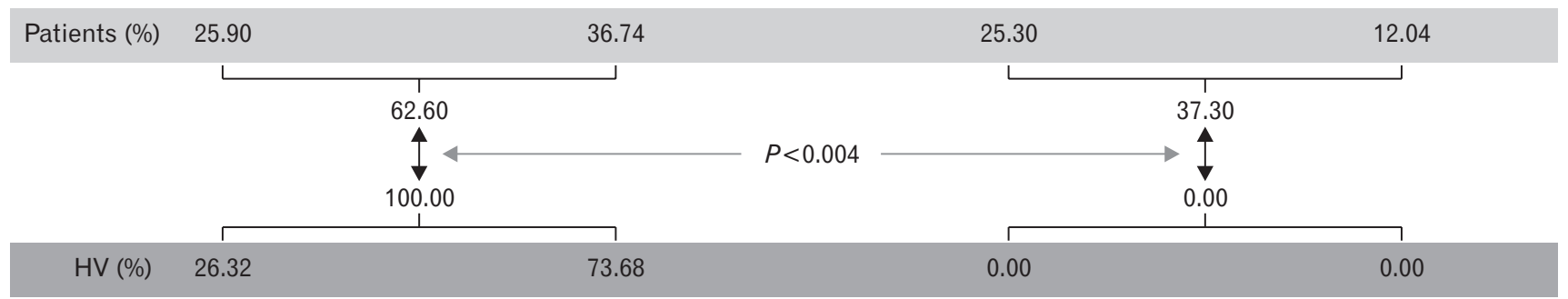

Figure 2. Endurance of mean voluntary squeeze pressure in patients with fecal incontinence compared with healthy volunteers (HV). All HV had effective squeeze profiles, compared to $62.60 \%$ of patients.

especially Type I (paradoxical EAS contraction). The mechanisms underlying $\mathrm{FI}$ in our patients as a result of the anorectal study with ARM are shown in Table 2. The most frequent dysfunction was EAS mechanical impairment.

RAIR was present in all patients and all HV. The mean volume of rectal distention needed to initiate RAIR in the patients was $20.00 \pm 7.33 \mathrm{~mL}$. HV needed smaller volumes to elicit RAIR $(14.74 \pm 5.13 ; P<0.001)$.

\section{Sphincter structural abnormalities}

EUS revealed that $37.14 \%$ (65) of patients had hypoechoic tears and defects in the puborectalis, $60.57 \%$ (106) in the EAS, and $34.85 \%$ (61), disruptions of the IAS. The predominant localization of damage affecting the puborectalis muscle, IAS and EAS was in the upper right quadrant (Fig. 3).

\section{Assessment of motor efferent pathways}

During ARM, EAS extrinsic reflex were present in all patients (and HV) but abnormally reduced in 24.69\% (41/166). Left PNTML was significantly delayed in patients with FI when compared with HV $(2.52 \pm 0.70 \mathrm{msec}$ vs $2.13 \pm 0.39 \mathrm{msec}, P=$ $0.013)$. There were no significant differences in the right PNTML between patients and $\mathrm{HV}(2.11 \pm 0.34 \mathrm{msec} v \mathrm{~s} 2.14 \pm 0.41 \mathrm{msec})$.
According to the normal cut-off of $2.80 \mathrm{msec}, 28.60 \%$ (12) of patients showed a delayed latency of the left pudendal nerve and $9.50 \%$ (4) of the right nerve. Overall, 33.30\% (14) of the patients with FI had delayed PNTML of at least one side.

\section{Assessment of anal and rectal sensory function}

According to reference values obtained from $\mathrm{HV}, 27.42 \%$ (48) of patients had impaired rectal sensitivity to rectal distention during ARM; $20.00 \%$ (35), hyposensitivity, and $7.42 \%$ (13), hypersensitivity. Mean values of distention to measure rectal perception are displayed in Table 3.

\section{Anal and rectal sensory evoked potentials}

Sensory thresholds. Thresholds to rectal and anal electrical stimulus were not significantly different for perception or for tolerance between HV and patients (Table 4). However, in a significant number of patients, threshold sensory values were above the reference interval: $39.47 \%$ (15/38) for rectal perception, 36.84\% (14/38) for anal perception and $10.52 \%$ (4/38) for anal tolerance.

Event-related sensory evoked potentials. As expected, HV showed a 4-peak SEP, with 2 positive and 2 negative peaks, of maximal scalp distribution at the vertex for both rectal and anal stimulation. In general terms, RSEP morphology was larger and 


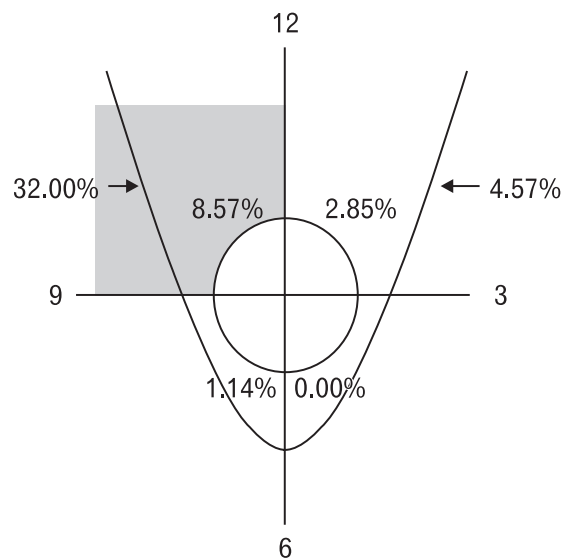

Proximal (deep) level (puborectalis and IAS)

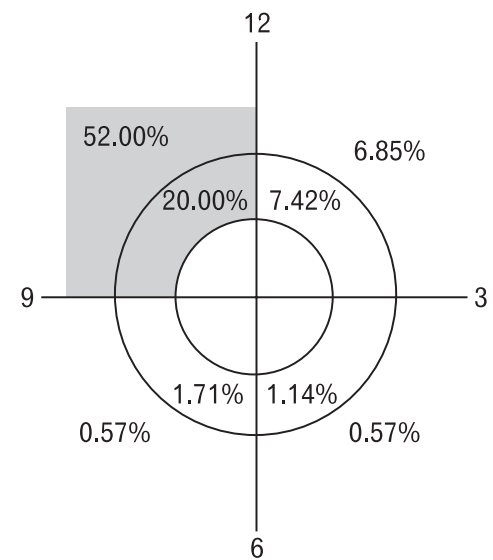

Middle (superficial) level (IAS and EAS)

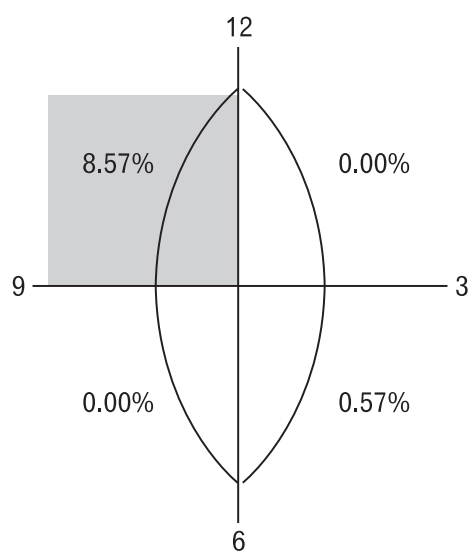

Distal (subcutaneous) level (EAS)

Figure 3. Structural abnormalities of the puborectalis muscle, internal anal sphincter (IAS), and external anal sphincter (EAS), in the deep, superficial, and subcutaneous levels along the anal canal. Note the predominance of muscle damage in the upper right quadrant.

Table 3. Mean Values of Rectal Sensitivity Parameters Acquired With Anorectal Manometry

\begin{tabular}{lccr}
\hline \multicolumn{1}{c}{ Parameter } & Patients & HV & $P$-value \\
\hline 1st sensation & $21.56 \pm 12.85$ & $15.26 \pm 6.11$ & 0.011 \\
1st feeling to pass stools & $48.28 \pm 27.39$ & $33.33 \pm 18.47$ & 0.013 \\
$\begin{array}{l}\text { Constant desire to } \\
\text { defecate }\end{array}$ & $67.99 \pm 31.86$ & $65.53 \pm 35.08$ & 0.610 \\
$\begin{array}{l}\text { Maximum tolerable } \\
\quad \text { volume }\end{array}$ & $100.40 \pm 46.58$ & $143.70 \pm 60.48$ & $<0.001$ \\
& & & \\
\hline
\end{tabular}

HV, healthy volunteers.

Values are expressed as mean $\pm \mathrm{SD}(\mathrm{mL})$.

narrower than ASEP, suggesting a length-dependent (from stimulation to recording site) higher synchronization of sensory inputs leading to RSEP. Significant within-group differences between RSEP and ASEP were found for $\mathrm{p} 1$ and $\mathrm{n} 1$ peak-latencies in HV as well as in patients, RSEP being longer than ASEP. Neurophysiological data on sensory thresholds and SEP are shown in Table 4. Representative SEP recordings and scalp distribution maps of individuals for each group are presented in Figure 4.

Anal sensory evoked potentials. ASEP latencies were significantly longer in patients than in HV for most peaks ( $\mathrm{p} 1$, p2, and n2), with no significant differences found for amplitude components (Table 4). We also found that $63.16 \%$ (24) of patients showed ASEP parameters outside the reference values $(50.00 \%$ for latency and $26.32 \%$ for amplitude).

Rectal sensory evoked potentials. As previously reported HV showed one of 2 types of RSEP morphologies: biphasic type
$\mathrm{A}$ in $36.36 \%$ (4/11) and monophasic type $\mathrm{B}$ in $63.63 \%(7 / 11) .{ }^{52} \mathrm{As}$ with ASEPs, RSEP latencies were significantly longer in patients than in HV for most peaks (n1, p2, and n2), with no significant differences in amplitude (Table 4). Moreover, in $50.00 \%$ of patients the RSEP parameters were outside the reference values (42.11\% [16] for latency and 31.80\% [12] for amplitude).

Correlations and additional analyses. A positive correlation of 1st anal perception and $\mathrm{n} 2$ peak-latency was found amongst HV ( $r=0.462, P=0.046)$, but not in patients. No other significant correlations were found either in patients or HV between SEP parameters and sensory landmarks on ARM or sensory thresholds to electrical stimulation. We also compared the RSEP of patients with $\mathrm{RH}$ with those with normal sensitivity measured with ARM. Patients with RH had significantly decreased N2P2 component compared with those patients with normal rectal sensitivity (2.10 \pm $1.89 \mu \mathrm{V}$ and $3.15 \pm 1.91 \mu \mathrm{V}$, respectively; $P=0.042$ ).

Sensory evoked potential source localization. Using sLORETA software, we compared the activated areas in the brain cortex after anorectal stimulation between $\mathrm{HV}$ and patients. In the $\mathrm{HV}$ group, the cortical areas that originated the activation after anal stimulation were located in the frontal lobe (inferior frontal gyrus for $\mathrm{p} 1, \mathrm{n} 1$, and $\mathrm{n} 2$, and superior frontal gyrus for $\mathrm{p} 2$, Brodmann areas [BA] 47 and 10, respectively). Cortical activated areas for the patients, however, were located at the superior frontal gyrus in the frontal lobe for $\mathrm{p} 1, \mathrm{n} 1$, and $\mathrm{n} 2$ (BA10) and in the middle temporal gyrus of the temporal lobe for $\mathrm{p} 2$ (BA21). Activated areas in $\mathrm{HV}$ were significantly broader when compared with patients (Fig. 5). Regarding rectal stimulation, the activated areas in the HV group 
Table 4. Sensory Evoked Potential Parameters After Anal and Rectal Stimulation

\begin{tabular}{|c|c|c|c|c|}
\hline \multicolumn{2}{|c|}{ Parameter } & \multirow[t]{2}{*}{$\mathrm{HV}$} & \multirow[t]{2}{*}{ Patients } & \multirow[t]{2}{*}{$P$-value } \\
\hline Anal stimulation & & & & \\
\hline \multirow[t]{2}{*}{ Sensory threshold (mA) } & Perception & $5.54 \pm 1.30$ & $9.93 \pm 8.85$ & 0.206 \\
\hline & Tolerance & $39.30 \pm 19.30$ & $36.63 \pm 25.47$ & 0.497 \\
\hline \multirow[t]{4}{*}{ ASEP latency (msec) } & p1 & $53.58 \pm 13.48$ & $64.53 \pm 15.26$ & 0.010 \\
\hline & $\mathrm{n} 1$ & $79.26 \pm 18.37$ & $90.68 \pm 18.11$ & 0.080 \\
\hline & $\mathrm{p} 2$ & $129.58 \pm 26.70$ & $156.40 \pm 30.72$ & 0.002 \\
\hline & $\mathrm{n} 2$ & $184.20 \pm 31.04$ & $212.60 \pm 33.56$ & 0.003 \\
\hline \multirow[t]{3}{*}{ ASEP amplitude $(\mu \mathrm{V})$} & p1-n1 & $1.92 \pm 1.25$ & $1.85 \pm 1.29$ & 0.634 \\
\hline & n1-p2 & $3.41 \pm 1.99$ & $3.98 \pm 2.37$ & 0.357 \\
\hline & $\mathrm{p} 2-\mathrm{n} 2$ & $3.66 \pm 2.13$ & $3.72 \pm 3.11$ & 0.553 \\
\hline \multicolumn{5}{|l|}{ Rectal stimulation } \\
\hline \multirow[t]{2}{*}{ Sensory threshold (mA) } & Perception & $25.65 \pm 10.22$ & $37.62 \pm 23.70$ & 0.111 \\
\hline & Tolerance & $79.36 \pm 15.44$ & $62.23 \pm 30.49$ & 0.095 \\
\hline \multirow[t]{4}{*}{ RSEP latency (msec) } & p1 & $62.91 \pm 13.20$ & $73.53 \pm 19.63$ & 0.059 \\
\hline & $\mathrm{n} 1$ & $91.33 \pm 14.31$ & $102.10 \pm 17.04$ & 0.023 \\
\hline & p2 & $140.92 \pm 27.81$ & $157.20 \pm 27.64$ & 0.016 \\
\hline & $\mathrm{n} 2$ & $171.34 \pm 27.72$ & $204.20 \pm 28.10$ & $<0.001$ \\
\hline \multirow[t]{3}{*}{ RSEP amplitude $(\mu \mathrm{V})$} & p1-n1 & $3.30 \pm 2.93$ & $2.54 \pm 2.23$ & 0.289 \\
\hline & n1-p2 & $3.97 \pm 3.75$ & $3.97 \pm 2.76$ & 0.718 \\
\hline & $\mathrm{p} 2-\mathrm{n} 2$ & $2.58 \pm 1.43$ & $2.96 \pm 1.90$ & 0.671 \\
\hline
\end{tabular}

HV, healthy volunteers; ASEP, anal sensory evoked potentials; RSEP, rectal sensory evoked potentials.

Values are expressed as mean $\pm \mathrm{SD}$.

were the superior frontal gyrus (BA10) for $\mathrm{p} 1, \mathrm{n} 1$, and $\mathrm{p} 2$, and the middle temporal gyrus (temporal lobe, BA21) for n2. For patients, cortex activation originated from the same areas except for $\mathrm{n} 1$, which was located in the postcentral gyrus of the parietal lobe (BA2). According to this analysis, cortical integration after rectal stimulation (n2) was weaker in patients with FI when compared with HV (Fig. 5).

\section{Discussion}

This study examined the pathophysiological mechanisms responsible for FI in women. We confirm that mechanical EAS and IAS dysfunctions-mainly related to obstetric factors-are very significant and well-known contributing factors for FI. The major findings from our study are that the previously unexplored delayed conduction through sensory anorectal pathways and secondary reduced cortical activation to electrical stimulation are also very prevalent pathophysiological factors for FI in women. The proportion of patients with FI with an afferent/sensory dysfunction was much higher in this study than those with peripheral pudendal motor conduction impairments, which is a well-known etiopathogenic mechanism for FI. This finding may help to develop more specific treatments for these patients.

Most of our patients had moderate to severe symptoms of FI which strongly affected FI-related QoL, and in turn impacted on health-related QoL, this general QoL being much better preserved in HV. Even when severity is moderate or mild, FI is very likely to affect QoL, with women appearing to be particularly affected. ${ }^{4} \mathrm{~Pa}-$ tients included in the present study are a representative sample of a cohort of patients with FI with severely impaired quality of life and health status attending a specialized incontinence clinic, looking for a specific diagnosis and effective treatment.

Obstetric factors are strongly associated with FI in women ${ }^{54}$ and symptoms usually appear years later when aging and hormonal changes associated with menopause occur. ${ }^{55}$ Large episiotomy, prolonged labor and use of forceps/spatula were factors much more prevalent in our patients compared with similar-aged HV. However, factors other than childbirth can be associated with FI. Pelvic organ prolapse, a condition that rarely occurs in isolation and strongly associated with FI and with urinary incontinence ${ }^{56,57}$ was present in almost half of our patients, and only one of our HV had a medical history of prolapse. Coloproctological proceedings were 
A Average group SEPs
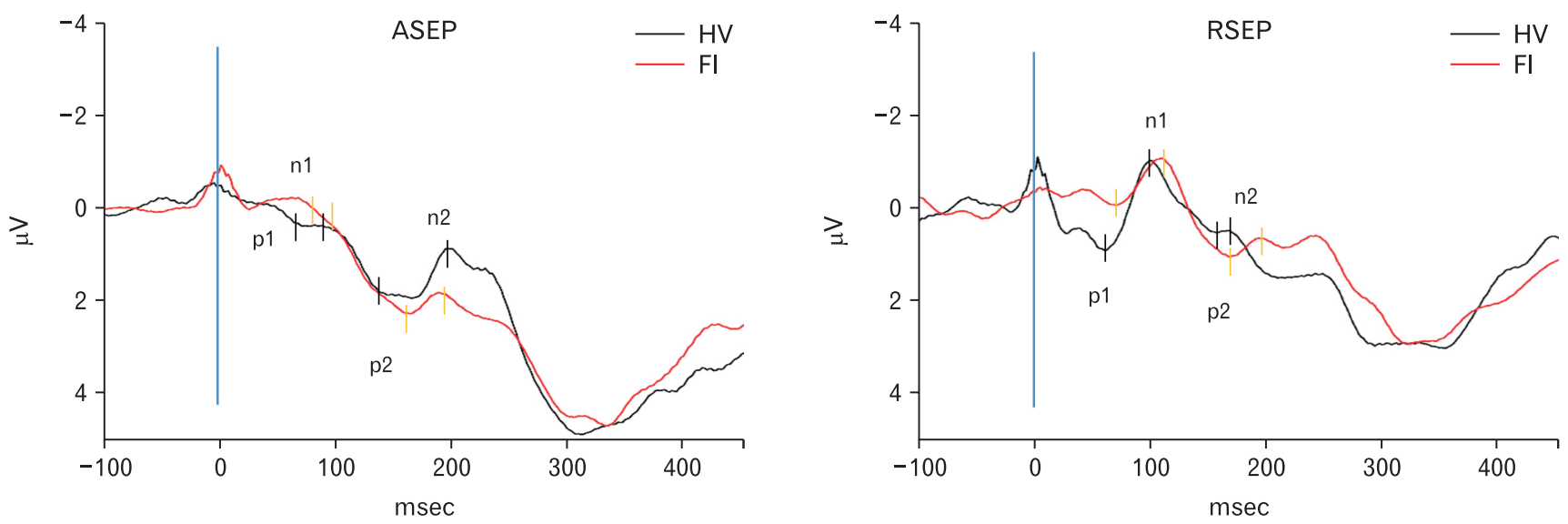

B Current peak-scalp distribution maps

HV
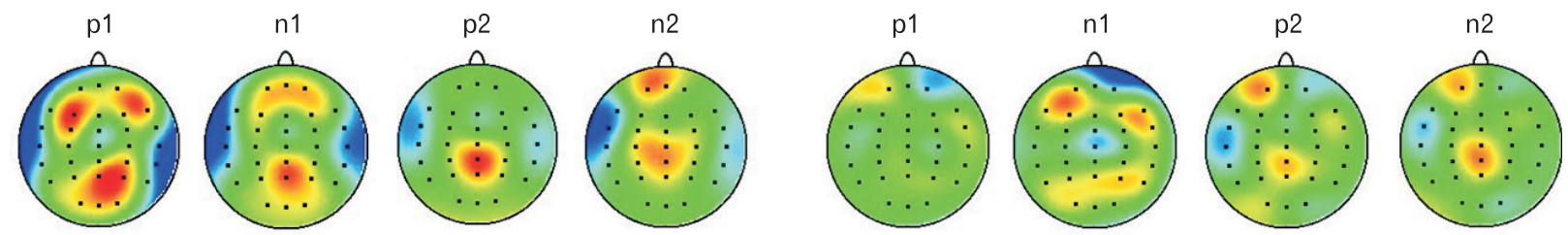

$\mathrm{FI}$
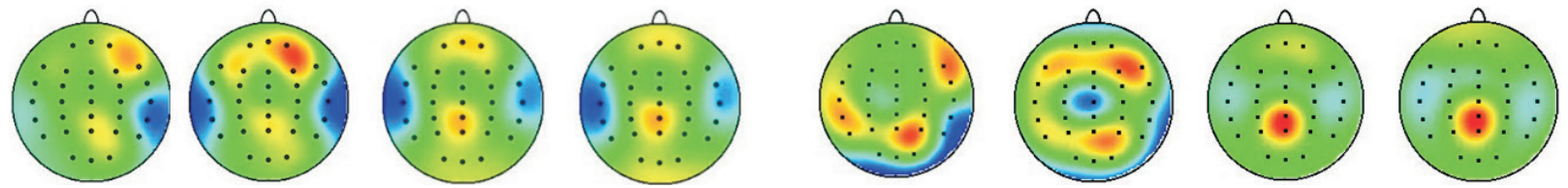

Figure 4. Sensory evoked potentials (SEPs) to electrical stimulation. (A) Anal and rectal sensory evoked potentials (ASEP and RSEP) recorded in patients with fecal incontinence (FI; solid red line) and in healthy volunteers (HV; solid black line) after anal and rectal stimulation, respectively; (B) current scalp density maps at each SEP peak time for HVs and patients.

ASEP

HV
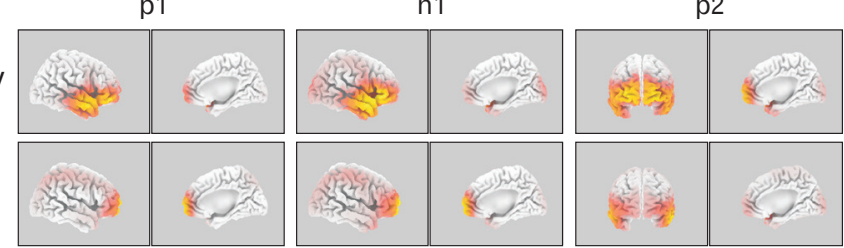

RSEP
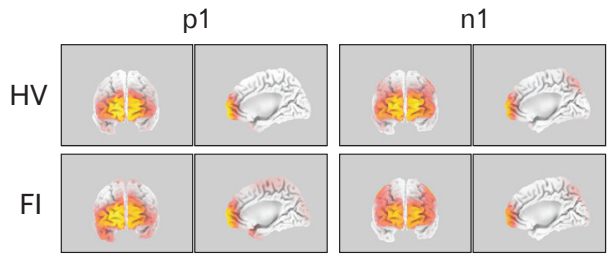

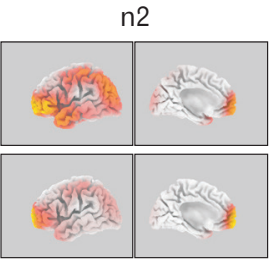

$\begin{array}{lllll}0.000 & 0.112 & 0.225 & 0.337 & 0.449\end{array}$
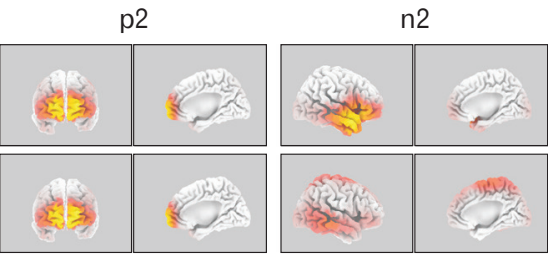

$\begin{array}{lllll}0.000 & 0.112 & 0.225 & 0.337 & 0.449\end{array}$
Figoure 5. sLORETA source activity comparing healthy volunteers (HV) with fecal incontinence (FI) patients for the evoked potentials to anal stimulation (top) and rectal stimulation (bottom) in the 4 peaks of anal sensory evoked potentials (ASEP) and rectal sensory evoked potentials (RSEP). ASEP cortical source activity was localized slightly higher in frontal lobe areas in patients compared with $\mathrm{HV}$ with a reduced overall area of cortical activation evidenced for most peaks. Differences in RSEP activation were not so clear between both groups except for source activity of $\mathrm{n} 2$ which showed diminished in FI patients. 
another major group of risk factors much more common in patients compared with $\mathrm{HV}^{58}$

While pelvic biomechanics has been the main mechanism commonly accepted as the cause of FI and the driving treatment, less attention has been paid to the role of fecal consistency. It is noteworthy that more than half the patients of this study had stools with Bristol $\geq 5$ (more than $20.00 \%$ Bristol 6 or 7 ), and only $3(15.70 \%)$ HV had this type of soft/loose stools. Lack of fecal consistency is associated to FI playing a fundamental role in continence - physiology has its limits - to the point that many patients with FI and loose stools stop having FI symptoms when fecal consistency is normalized. ${ }^{59}$ Concurrence with other important factors involved in continence, like sphincter weakness, and impaired sensory function, usually causes severe leakage symptoms. So, proper diagnosis and treatment of excessively soft stools should be performed before attempting any FI rehabilitation strategy. ${ }^{60}$

Regarding the mechanical factors commonly associated with FI, our study corroborates the high prevalence of mechanical sphincter insufficiency, especially EAS—due to muscle tears or neural damage - when compared with HV. To these findings we can add the importance of MVSP endurance-not commonly recorded in clinical studies - as a key factor in maintaining continence. EAS endurance is related to the activity of the muscle type I (slow-twitch) fibers, as opposed to the type II fibers, which ensure a rapid contractile response to the EAS. ${ }^{61}$ The proportion and fitness of slow-twitch fibers in FI patients may be lower than in HV. Maintaining squeezing over time is as important as maximal squeeze, and deferring defecation, has much to do with maintaining squeeze over a significant length of time. In that regard, almost $40 \%$ of our patients showed ineffective pressure patterns during sustained squeeze and in contrast, all HV showed well-sustained pressure patterns.

Prevalence of sphincter tears was higher than motor neuropathy as a cause of EAS insufficiency. EUS showed that many of our patients had tears in the EAS and puborectalis or IAS disruption, which could partly explain the mechanical impairment we observed and, eventually, FI. Most of those injuries were obstetric-related and it is important to notice the predominance in the upper right quadrant, which suggests they were due to mediolateral episiotomies practiced by right-handed obstetricians. EAS and puborectalis impairment can also be associated with pudendal motor neuropathy. In that regard, one quarter of patients had impaired cough reflexa result that is related to the one third of patients assessed with PNTML that showed delayed terminal latency. The use of PNT$\mathrm{ML}^{62}$ has not been extensive due to several issues like poor sensitivity ${ }^{50}$ operator-dependability, and due to the fact that it measures the conduction of the fastest nerve fibres, ${ }^{63}$ so a normal PNTML does not necessarily indicate indemnity of pudendal motor fibers. However, it is a non-expensive and quick procedure which can give some insight to possible motor neural dysfunctions. Alternatively, motor evoked potentials, recorded from pelvic floor structures to transcranial magnetic stimulation, enable exploration of the efferent pathway along their entire length and avoid some of the pitfalls of PNTML, but are a costly and cumbersome procedure. Motor neuropathy in FI has been associated with excessive pelvic descent during labor, and also it has been reported that straining caused by dyssynergia can also damage the sphincter function and contribute to FI, although we did not find significant results regarding these relationships. ${ }^{64}$ It is noteworthy that almost the same percentage of HV showed similar dyssynergic evacuatory patterns, without complaints of constipation nor FI.

Regarding sensorial aspects, more than a quarter of patients had rectal sensitivity impairments, especially hyposensitivity. Overall, our patients with FI needed higher volumes of rectal distention compared with HV to evoke most sensorial landmarks commonly evaluated during ARM. They also needed greater rectal distension to start RAIR, which suggests an increase in rectal compliance which may also affect rectal sensitivity. As some other studies have reflected, ${ }^{65,66}$ intact rectal sensitivity plays a key role in rectoanal coordination and in maintaining continence, that is, individuals must be sensory-aware to properly trigger continence mechanisms. Sensitivity results obtained by means of ARM reflect rectal mechanoreceptors' distension sensitivity, but cannot clarify whether afferent neural pathway dysfunction exists (primary hyposensitivity ${ }^{67}$ ). To date, very few studies have explored the role of afferent pathways in patients with FI, and with inconclusive results. ${ }^{30}$ In this study, SEP morphology in response to electrical stimulus in healthy subjects was similar to that observed in previous studies ${ }^{32,35}$ and showed that both anal and rectal SEP peak-latencies to electrical stimulation of anorectal structures were longer in patients compared with HV, with significant differences in most of these parameters. According to our normative values, $63 \%$ of patients showed impaired ASEP (delayed latency and/or diminished amplitudes) and 50\%, RSEP. The positive correlation of $\mathrm{n} 2$ ASEP peak-latency with 1st perception threshold (ie, earlier perception in more aware subjects) found in $\mathrm{HV}$ was not present in the group of patients. This physiological correlation, lost in patients with FI, hints the importance of anal sensitivity in continence. On the other hand, the decreased RSEP $\mathrm{n} 2 \mathrm{p} 2$ component in patients with $\mathrm{RH}$ points to impaired integration of anorectal sensory inputs. Overall, afferent sensory dysfunction, which implies an impaired perception of anorectal stimuli, may 
lead to a loss of motor control and, eventually to FI. Therefore, this probably has a major role in the pathophysiology of many patients with FI. The prevalence of sensory impairment in our patients was higher than that of impairments in the terminal motor pathways, which represented $33.3 \%$ of the patients evaluated. Also, individual peak-scalp distribution maps findings and further confirmation through sLORETA reconstruction of group brain source activation indicated broader activation of cortical areas after anal stimulation in HV compared with patients and worse cortical sensory activation after rectal stimulation in patients with FI. These last findings do not implicate the brain cortex as the origin of pathophysiological mechanisms that lead to FI; rather they represent ancillary phenomena of final CNS activation, probably related to impaired sensory perception and integration processing, after full stimulation of sensory afferents of the anorectum. Although the localization of that impairment cannot be identified precisely with the SEP methodology we used, because of our patient's clinical phenotype, it is highly probable that it is due to damage of sensory fibers of the pudendal nerve. However, we cannot rule out that compensatory neuroplastic mechanisms in the cerebral cortex contribute to the reduced pattern of brain activation in patients with $\mathrm{FI}$.

Technical limitations in SEPs reproducibility have been reported previously and could compromise clinical applicability of sensory assessment in individual subjects. Incomplete contact of the electrode probe with rectal mucosa, the known higher contribution of post-conduction high-level processing phenomena than conduction properties to acquisition of long-latency event-related SEPs, are some examples. In fact, we aimed to prove that sensory impairment of anorectal afferents could be a contributing factor to FI pathophysiology rather than to demonstrate clinical applicability of SEPs methodology.

In conclusion, FI is still a major clinical challenge with unmet diagnostic and therapeutic needs. Fecal continence requires the proper functioning of several mechanisms: sensory capacity and the action and coordination of muscle groups. Beyond the motor and sensitive function of the pelvic elements, we have explored the afferent conduction and cortical activation involved in patients with FI, and we have demonstrated that a very high percentage of women with FI have afferent pathway impairment. The pathophysiology of FI is not yet fully understood and needs further research. Studies exploring the clinical significance of afferent pathway dysfunction and its association with other pathophysiological factors must be conducted. Our study may also help explain the effects of recent neuromodulation techniques in improving FI symptoms in some patients without any major mechanical effect on sphincter function.
Acknowledgements: We acknowledge Dr Mateu Serra and Elisabet Palomera for their statistical support and counselling, and Jane Lewis for assistance with the English.

Financial support: Part of this research was funded through a PERIS grant from Catalonian Health Department (SLT002/16/00214). Ciberehd is founded by Instituto de Salud Carlos III, Barcelona, Spain.

\section{Conflicts of interest: None.}

Author contributions: Lluís Mundet: performed study design, research and data acquisition, data analysis, and paper writing; Christopher Cabib: performed neurophysiological analysis (EEG) and paper writing; Omar Ortega: performed data acquisition; Laia Rofes: performed study design and data acquisition; Noemi Tomsen: performed data analysis (sLORETA); Sergio Marin and Carla Chacon: performed data acquisition; and Pere Clavé: performed study design and paper writing.

\section{References}

1. Norton C. Nurses, bowel continence, stigma, and taboos. J Wound Ostomy Continence Nurs 2004;31:85-94.

2. Bartlett L, Nowak M, Ho YH. Impact of fecal incontinence on quality of life. World J Gastroenterol 2009;15:3276-3282.

3. Collings S, Norton C. Women's experiences of faecal incontinence: a study. Br J Community Nurs 2004;9:520-523.

4. Mundet L, Ribas Y, Arco S, Clavé P. Quality of life differences in female and male patients with fecal incontinence. J Neurogastroenterol Motil 2016;22:94-101

5. Bordeianou L, Rockwood T, Baxter N, Lowry A, Mellgren A, Parker S. Does incontinence severity correlate with quality of life? Prospective analysis of 502 consecutive patients. Colorectal Dis 2008;10:273-279.

6. Ciriza de Los Ríos C, Ruiz de León A, García Duran F, et al. [Quality of life and its association with the severity of fecal incontinence]. Gastroenterol Hepatol 2010;33:621-628. [Spanish]

7. Bharucha AE, Dunivan G, Goode PS, et al. Epidemiology, pathophysiology, and classification of fecal incontinence: state of the science summary for the National Institute of Diabetes and Digestive and Kidney Diseases (NIDDK) workshop. Am J Gastroenterol 2015;110:127-136.

8. Nelson RL. Epidemiology of fecal incontinence. Gastroenterology 2004;126(1 suppl 1):S3-S7

9. Lam, Kennedy, Chen, Lubowski, Talley. Prevalence of faecal incontinence: obstetric and constipation-related risk factors; a population-based study. Colorectal Dis 1999;1:197-203.

10. Parés D, Vial M, Bohle B, et al. Prevalence of faecal incontinence and analysis of its impact on quality of life and mental health. Colorectal Dis 2011;13:899-905.

11. Alsheik EH, Coyne T, Hawes SK, et al. Fecal incontinence: prevalence, 
severity, and quality of life data from an outpatient gastroenterology practice. Gastroenterol Res Pract 2012;2012:947694.

12. Nelson R, Norton N, Cautley E, Furner S. Community-based prevalence of anal incontinence. JAMA 1995;274:559-561.

13. Walter S, Hallböök O, Gotthard R, Bergmark M, Sjödahl R. A population-based study on bowel habits in a Swedish community: prevalence of faecal incontinence and constipation. Scand J Gastroenterol 2002;37:911916.

14. Lim JW, Heng C, Wong MT, Tang CL. Prevalence of faecal incontinence in the community: a cross-sectional study in Singapore. Singapore Med J 2014;55:640-643.

15. Kamm MA. Obstetric damage and faecal incontinence. Lancet 1994;344:730-733.

16. Sultan AH, Kamm MA, Hudson CN, Thomas JM, Bartram CI. Anal-sphincter disruption during vaginal delivery. N Engl J Med 1993;329:1905-1911.

17. Perry S, Shaw C, McGrother C, et al. Prevalence of faecal incontinence in adults aged 40 years or more living in the community. Gut 2002;50:480484.

18. Quander CR, Morris MC, Melson J, Bienias JL, Evans DA. Prevalence of and factors associated with fecal incontinence in a large community study of older individuals. Am J Gastroenterol 2005;100:905-909.

19. Whitehead WE, Borrud L, Goode PS, et al. Fecal incontinence in US adults: epidemiology and risk factors. Gastroenterology 2009;137:512517, 517, e1-e2.

20. Varma MG, Brown JS, Creasman JM, et al. Fecal incontinence in females older than aged 40 years: who is at risk? Dis Colon Rectum 2006;49:841-851.

21. Phillips J, Lees N, Arnall F. Current management of fistula-in-ano. Br J Hosp Med (Lond) 2015;76:142, 144-147.

22. Nyam DC, Pemberton JH. Long-term results of lateral internal sphincterotomy for chronic anal fissure with particular reference to incidence of fecal incontinence. Dis Colon Rectum 1999;42:1306-1310.

23. Li YD, Xu JH, Lin JJ, Zhu WF. Excisional hemorrhoidal surgery and its effect on anal continence. World J Gastroenterol 2012;18:4059-4063.

24. Tiainen J, Matikainen M. Health-related quality of life after ileal Jpouch-anal anastomosis for ulcerative colitis: long-term results. Scand J Gastroenterol 1999;34:601-605.

25. Hamilton AS, Stanford JL, Gilliland FD, et al. Health outcomes after external-beam radiation therapy for clinically localized prostate cancer: results from the Prostate Cancer Outcomes Study. J Clin Oncol 2001;19:2517-2526.

26. Bytzer P, Talley NJ, Leemon M, Young LJ, Jones MP, Horowitz M. Prevalence of gastrointestinal symptoms associated with diabetes mellitus: a population-based survey of 15,000 adults. Arch Intern Med 2001;161:1989-1996.

27. Caruana BJ, Wald A, Hinds JP, Eidelman BH. Anorectal sensory and motor function in neurogenic fecal incontinence. Comparison between multiple sclerosis and diabetes mellitus. Gastroenterology 1991;100:465470.

28. Norton C. Conservative and pharmacological management of faecal incontinence in adults. Incontinence 2009;1321-1386.
29. Rao SS, Azpiroz F, Diamant N, Enck P, Tougas G, Wald A. Minimum standards of anorectal manometry. Neurogastroenterol Motil 2002;14:553-559.

30. Speakman CT, Kamm MA, Swash M. Rectal sensory evoked potentials: an assessment of their clinical value. Int J Colorectal Dis 1993;8:23-28.

31. Burgell RE, Scott SM. Rectal hyposensitivity. J Neurogastroenterol Motil 2012;18:373-384.

32. Remes-Troche JM, Tantiphlachiva K, Attaluri A, et al. A bi-directional assessment of the human brain-anorectal axis. Neurogastroenterol Motil 2011;23:240-248, e117-e118.

33. Hobday DI, Hobson AR, Sarkar S, Furlong PL, Thompson DG, Aziz Q. Cortical processing of human gut sensation: an evoked potential study. Am J Physiol Gastrointest Liver Physiol 2002;283:G335-G339.

34. Loening-Baucke V, Read NW, Yamada T. Further evaluation of the afferent nervous pathways from the rectum. Am J Physiol 1992;262(5 Pt 1):G927-G933.

35. Burgell RE, Lelic D, Carrington EV, et al. Assessment of rectal afferent neuronal function and brain activity in patients with constipation and rectal hyposensitivity. Neurogastroenterol Motil 2013;25:260-267, e167e168.

36. Haas S, Faaborg P, Gram M, et al. Abnormal neuronal response to rectal and anal stimuli in patients treated with primary radiotherapy for anal cancer. Radiother Oncol 2018;128:369-374.

37. Jorge JM, Wexner SD. Etiology and management of fecal incontinence. Dis Colon Rectum 1993;36:77-97.

38. Minguez M, Garrigues V, Soria MJ, Andreu M, Mearin F, Clave P. Adaptation to Spanish language and validation of the fecal incontinence quality of life scale. Dis Colon Rectum 2006;49:490-499.

39. Rockwood TH, Church JM, Fleshman JW, et al. Fecal Incontinence Quality of Life Scale: quality of life instrument for patients with fecal incontinence. Dis Colon Rectum 2000;43:9-16; discussion 16-17.

40. Rabin R, de Charro F. EQ-5D: a measure of health status from the EuroQol Group. Ann Med 2001;33:337-343.

41. Grucela A, Gurland B, Kiran RP. Functional outcomes and quality of life after anorectal surgery. Am Surg 2012;78:952-956.

42. Koch SM, Melenhorst J, Uludağ O, et al. Sacral nerve modulation and other treatments in patients with faecal incontinence after unsuccessful pelvic floor rehabilitation: a prospective study. Colorectal Dis 2010;12:334-341.

43. Baden WF, Walker TA. Genesis of the vaginal profile: a correlated classification of vaginal relaxation. Clin Obstet Gynecol 1972;15:1048-1054.

44. Lewis SJ, Heaton KW. Stool form scale as a useful guide to intestinal transit time. Scand J Gastroenterol 1997;32:920-924.

45. Avery K, Donovan J, Peters TJ, Shaw C, Gotoh M, Abrams P. ICIQ: a brief and robust measure for evaluating the symptoms and impact of urinary incontinence. Neurourol Urodyn 2004;23:322-330.

46. Mundet i Pons L. Estudi de l'eficàcia dels tractaments per a la incontinència fecal en dones adultes residents a la comunitat: avaluació de l'eficàcia individual sobre la fisiologia anorectal i la plasticitat cortical cerebral, l'impacte en la severitat clínica i en la qualitat de vida. Barcelona: Universitat Autònoma de Barcelona 2017.

47. Lacima G, Serra J, Minguez M, Accarino A. Tratado de neurogastroen- 
terología y motilidad digestiva. Madrid: Editorial Medica Panamericana 2015.

48. Abdool Z, Sultan AH, Thakar R. Ultrasound imaging of the anal sphincter complex: a review. Br J Radiol 2012;85:865-875.

49. Rogers J, Henry MM, Misiewicz JJ. Disposable pudendal nerve stimulator: evaluation of the standard instrument and new device. Gut 1988;29:1131-1133.

50. Lefaucheur JP. Neurophysiological testing in anorectal disorders. Muscle Nerve 2006;33:324-333.

51. Nockolds CL, Hosker GL, Kiff ES. Compound muscle action potential of the external anal sphincter. Colorectal Dis 2013;15:1289-1294.

52. Hobday DI, Aziz Q, Thacker N, Hollander I, Jackson A, Thompson DG. A study of the cortical processing of ano-rectal sensation using functional MRI. Brain 2001;124:361-368.

53. Pascual-Marqui RD, Michel CM, Lehmann D. Low resolution electromagnetic tomography: a new method for localizing electrical activity in the brain. Int J Psychophysiol 1994;18:49-65.

54. Lunniss PJ, Gladman MA, Hetzer FH, Williams NS, Scott SM. Risk factors in acquired faecal incontinence. J R Soc Med 2004;97:111-116.

55. Bohle B, Belvis F, Vial M, et al. Menopause and obstetric history as risk factors for fecal incontinence in women. Dis Colon Rectum 2011;54:975981.

56. Zeleke BM, Bell RJ, Billah B, Davis SR. Symptomatic pelvic floor disorders in community-dwelling older Australian women. Maturitas 2016;85:34-41.

57. Uustal Fornell E, Wingren G, Kjølhede P. Factors associated with pelvic floor dysfunction with emphasis on urinary and fecal incontinence and genital prolapse: an epidemiological study. Acta Obstet Gynecol Scand 2004;83:383-389.
58. Hayden DM, Weiss EG. Fecal incontinence: etiology, evaluation, and treatment. Clin Colon Rectal Surg 2011;24:64-70.

59. Bharucha AE, Zinsmeister AR, Schleck CD, Melton LJ 3rd. Bowel disturbances are the most important risk factors for late onset fecal incontinence: a population-based case-control study in women. Gastroenterology 2010;139:1559-1566.

60. Fernández-Bañares F, Esteve M, Salas A, et al. Systematic evaluation of the causes of chronic watery diarrhea with functional characteristics. Am J Gastroenterol 2007;102:2520-2528.

61. Raizada V, Mittal RK. Pelvic floor anatomy and applied physiology. Gastroenterol Clin North Am 2008;37:493-509, vii.

62. Kiff ES, Swash M. Normal proximal and delayed distal conduction in the pudendal nerves of patients with idiopathic (neurogenic) faecal incontinence. J Neurol Neurosurg Psychiatry 1984;47:820-823.

63. Tillakaratne M SD. The role of Pudendal Nerve Terminal Motor Latency (PNTML) in the assessment of the external anal sphincter function. Galle Medical Journal 2009;11:3-6.

64. Amselem C, Puigdollers A, Azpiroz F, et al. Constipation: a potential cause of pelvic floor damage? Neurogastroenterol Motil 2010;22:150153, e48.

65. Wald A, Tunuguntla AK. Anorectal sensorimotor dysfunction in fecal incontinence and diabetes mellitus. Modification with biofeedback therapy. N Engl J Med 1984;310:1282-1287.

66. Read MG, Read NW. Role of anorectal sensation in preserving continence. Gut 1982;23:345-347.

67. Gladman MA, Aziz Q, Scott SM, Williams NS, Lunniss PJ. Rectal hyposensitivity: pathophysiological mechanisms. Neurogastroenterol Motil 2009;21:508-516, e4-e5. 